DEPARTMENT OF COMMERCE

BUREAU OF STANDARDS

George K. Burgess, Director

TECHNOLOGIC PAPERS OF THE BUREAU OF STANDARDS, No. 339

[Part of Vol. 21]

\title{
USE OF SULPHITE CELLULOSE EXTRACT AS A TANNING MATERIAL
}

E. L. WALLACE, Associate Physicist

R. C. BOWKER, Physicist

Bureau of Siandards

APRLL 5,1927

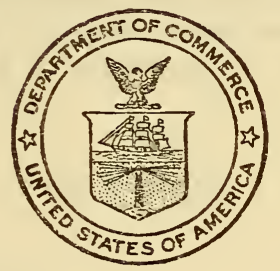

PRICE 30 CENTS

\$1.25 PER VOLUME ON SUbSCRIPTION

Sold only by the Superintendent of Documents, Government Printing Office Washington, D.C.

UNITED STATES

GOVERNMENT PRINTING OFFICE

WASHINGTON

1927 


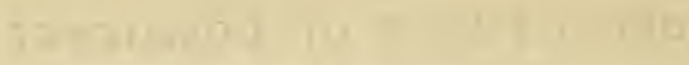

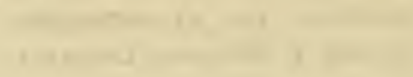

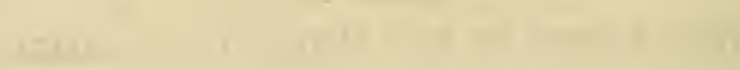

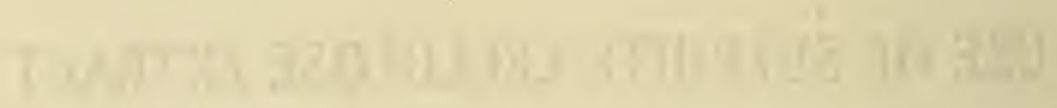

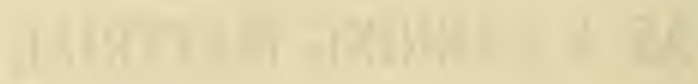
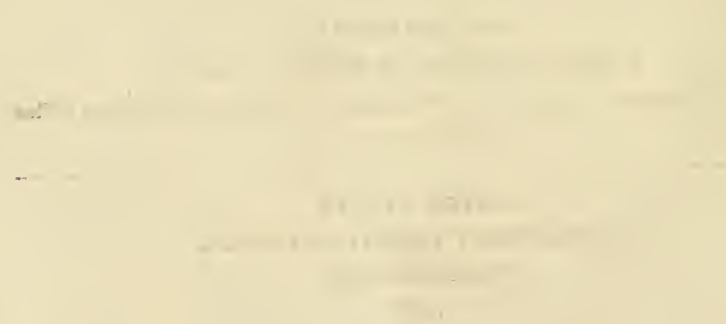


\title{
USE OF SULPHITE CELLULOSE EXTRACT AS A TANNING MATERIAL
}

\author{
By E. L. Wallace and R. C. Bowker
}

\section{ABSTRACT}

An investigation was conducted to determine the suitability of sulphite cellulose extracts, derived from the waste liquors discharged from paper pulp mills, for use in tanning hides for the manufacture of leather. The work included an analysis of various extracts for tannin content in comparison with vegetable tanning materials. Information regarding the combination of the tannins in these extracts with hide substance is presented, derived from actual tanning tests on both hide powder and pieces of raw hide.

The results show that these extracts contain materials absorbable by hide powder in quantities which compare favorably with the amounts found in the ordinary vegetable tanning materials. Tanning tests on light skins show that the extracts are satisfactory in so far as color is concerned. Tests with hide powder showed that the materials in these extracts available for leather making are firmly held by hide substance, and actual tanning experiments with hide pieces demonstrate that they have a satisfactory tanning value, particularly when blended with other vegetable extracts. The chemical, physical, and aging properties of the tanned leathers compare favorably with those of leathers prepared without the use of these extracts.

It is concluded that sulphite cellulose extracts are suitable for use in the actual tanning processes, and that the tanner may benefit from their use to the extent that they may be substituted for more costly materials. Their use also is of direct advantage to the paper-pulp producer in that it will aid in solving the waste-disposal problem.

\section{CONTENTS}

I. Introduction

II. Purpose of the investigation...

III. Source of sulphite cellulose extract......

IV. Methods and results........... 312

1. Analyses of sulphite cellulose extracts............... 312

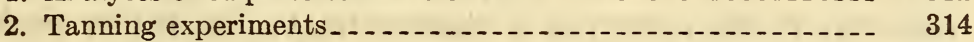

(a) Color tests.......... 314

(b) Hide-powder tests ............. 315

(c) Blends with vegetable extracts................ 316

(d) Pretanning experiments.................... 317

(e) Tanning with blended liquors............. 319

(f) Evaluation of tanned leather.... . . . . . . . . .... 320

3. Summary . . . . . .

V. Conclusion

$\begin{array}{ll}33464^{\circ}-27 & 309\end{array}$ 


\section{INTRODUCTION}

Among the many materials which have been investigated for use in the tanning of hides, one class has stood out prominently as a fruitful field for research in view of the cheapness with which production and distribution may be accomplished as compared with the ordinarily used vegetable tanning materials. Reference is made to sulphite cellulose extracts which are prepared from the waste sulphite liquors discharged from mills engaged in the manufacture of paper pulp. At the present time these extracts are recognized commercial products and find a steady use in the filling and extracting operations accompanying the manufacture of sole leather after the actual tannage has been completed. Investigations made by this bureau ${ }^{1}$ showed that leather filled with sulphite cellulose extract wore equally as well as leather filled with the ordinary vegetable materials, such as chestnut wood and quebracho extracts. Samples of these leathers, stored in the laboratory for six years, show no detrimental effects of aging. The suitability of sulphite cellulose extracts for use in the filling stages in sole-leather manufacture being established, it appeared logical to investigate its suitability for use in the tanning stages.

Its successful application in the tanning processes would be beneficial in many ways. It would provide the tanner with a cheap raw material which could be substituted, at least in part, for some of the more expensive materials now used, thereby lowering his production costs. Its utilization would eliminate waste to the advantage of the paper pulp producers and also modify the dependence of the tanning industry on imported tanning materials.

\section{PURPOSE OF THE INVESTIGATION}

The direct purpose of this investigation was to determine the suitability of sulphite cellulose extracts for use in the actual tanning processes by means of practical tanning tests, together with such chemical and physical studies as would assist in the evalution of the tanning properties of these materials. It has been generally stated that sulphite cellulose extracts do not contain true tannins similar in structure to those contained in the ordinary regetable tanning materials. It is not the purpose of this investigation to study the structure of the materials in these extracts, but rather to determine their suitability for use as tanning materials. Therefore, it should be borne in mind that, when the term "tannins" is mentioned in connection with these extracts, the materials meant are those absorbable by hide powder as determined by methods generally employed in commerce for all vegetable tanning materials. It is fully realized

${ }^{1}$ Bureau of Standards Tech. Paper No. 215, Durability of Sole Leather Filled with Sulphite Cellulose Extract, June 10, 1922. 
that the experiments to be described were conducted under laboratory conditions somewhat different from those which occur in actual tannery practice. It is, therefore, intended to present the results of the investigation for the use of those who are interested in conducting tests on a larger scale in the tannery.

\section{SOURCE OF SULPHITE CELLULOSE EXTRACT}

It is considered desirable to state briefly and in general terms the procedure by which sulphite cellulose extracts are made in order that their nature may be better understood. A common method of making paper pulp is to digest the wood from fir and spruce trees with an aqueous solution of an acid sulphite. This sulphite can be made with sodium, calcium, or magnesium as a base, but usually either calcite or dolomite lime is employed. When the latter is used the liquor contains dissolved acid sulphites of both calcium and magnesium. In the digestion of the wood the cellulose is left in insoluble form for use as paper pulp and the sulphites mostly disappear as such due to reaction with other organic matter in the wood. Other organic materials enter into combination with the bases of the sulphite liquor and remain in solution in the digestor. This solution is termed the sulphite waste liquor, in which form it has no value for use in the tanning of hides.

To produce an extract suitable for use in leather manufacture, the sulphite waste liquor, which is acid, is neutralized with a slight excess of dolomite lime. It being desirable that a tanning material be reasonably free from lime, the latter is precipitated with the calculated amount of sulphuric acid. The precipitate is then removed by filtration and the residual liquor is concentrated to the desired density (usually about $30^{\circ} \mathrm{B}$.). The extract thus produced compares favorably with ordinary vegetable tanning materials both as to content of soluble solids and as to the percentage of material absorbable by hide powder. Whereas the exact character of the constituents in sulphite cellulose extracts which have tanning properties is not known, they are termed "lignosulphonic acids" because of the probable formation of compounds between the acid sulphites and the "lignone" portions of the wood.

There are described in the literature many methods for producing a sulphite cellulose extract where the kinds and quantities of materials are varied as well as the steps in the process. The above, however, will serve to illustrate in a general way the preparation of this material from the waste sulphite liquor. 


\section{METHODS AND RESULTS}

A study of the suitability for use in tanning of any material from a vegetable source is made difficult because of the lack of knowledge regarding the exact constitution of the compounds present which are desirable and which accomplish the tanning. In view of this condition, the term "tannins" in commerce has come to mean that portion of a material which will combine with hide powder when the latter is treated with a solution of the tanning material, of concentration confined to certain limits, until the solution will no longer give a precipitate with gelatin. Having determined by this empirical method that a material contains a promising amount of matter absorbable by hide powder, the final test lies in the results of practical tanning experiments. The work to be described deals largely with tanning tests and the evaluation of the leather produced, together with a chemical examination of the sulphite cellulose extracts. In many of the experiments three or four different extracts were used and they will be identified by the numbers $1,2,3$, and 4 .

\section{ANALYSES OF SULPHite CELLULOSE EXTRACTS}

In Table 1 will be found the results of chemical analyses made on four samples of sulphite cellulose extracts. In determining the tannin content the official method of the American Leather Chemists' Association was used.

TABLE 1.-Results of analyses of sulphite cellulose extracts

\begin{tabular}{|c|c|c|c|c|}
\hline & No. 1 & No. 2 & No. 3 & No. 4 \\
\hline 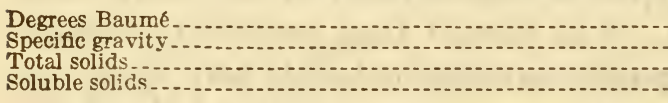 & $\begin{array}{l}29.80 \\
1.261 \\
53.13 \\
53.13\end{array}$ & $\begin{array}{l}30.00 \\
1.263 \\
53.00 \\
53.00\end{array}$ & $\begin{array}{l}28.80 \\
1.250 \\
49.80 \\
49.80\end{array}$ & $\begin{array}{l}29.30 \\
1.255 \\
49.96 \\
47.58\end{array}$ \\
\hline $\begin{array}{l}\text { Tannins } \\
\text { Nontannins } \\
\text { Insolubles } \\
\text { Water }\end{array}$ & $\begin{array}{r}28.33 \\
24.80 \\
.00 \\
46.87\end{array}$ & $\begin{array}{r}28.79 \\
24.21 \\
47.00\end{array}$ & $\begin{array}{r}25.98 \\
23.82 \\
50.00\end{array}$ & $\begin{array}{r}28.90 \\
18.68 \\
2.38 \\
50.04\end{array}$ \\
\hline $\begin{array}{l}\text { Ash } \\
\mathrm{Lime} \text { as } \mathrm{Ca} \mathrm{O} \text { O } \mathrm{MgO} \mathrm{O} \\
\text { Iron and aluminum as } \mathrm{R}_{2} \mathrm{O}_{3}\end{array}$ & $\begin{array}{r}4.13 \\
.34 \\
1.89 \\
.27\end{array}$ & $\begin{array}{r}3.53 \\
.22 \\
1.47 \\
.01\end{array}$ & $\begin{array}{r}4.20 \\
.21 \\
1.08 \\
1.40\end{array}$ & $\begin{array}{r}3.10 \\
.20 \\
.10 \\
2.20\end{array}$ \\
\hline $\begin{array}{l}\text { Iron as } \mathrm{Fe}_{2} \mathrm{O}_{3} \\
\text { Purity } 1 \\
\text { Ph value (analytical strength) } \\
\text { Acid as acetic }\end{array}$ & $\begin{array}{r}.01 \\
53.40 \\
3.50 \\
2.28\end{array}$ & $\begin{array}{l}.005 \\
54.30 \\
2.86 \\
3.61\end{array}$ & $\begin{array}{l}52.028 \\
3.40 \\
3.00\end{array}$ & $\begin{array}{r}.00 \\
60.80 \\
3.48 \\
6.70\end{array}$ \\
\hline
\end{tabular}

1 Purity is expressed as the percentage of the total solid matter present which can be taken up by hide substance.

The results show that these extracts contain tannin contents, as determined by the generally accepted method, which compare favorably with the amounts found in other commonly used materials. In Table 2 the tannin content, nontannin content, and purity are 
given for several of the vegetable tanning extracts in comparison with the sulphite cellulose extracts.

TABLE 2.-Tannin contents in per cent

\begin{tabular}{|c|c|c|c|}
\hline 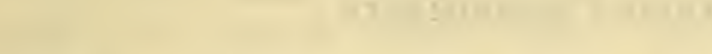 & Tannin & $\begin{array}{c}\text { Non- } \\
\text { tannin }\end{array}$ & Purity \\
\hline 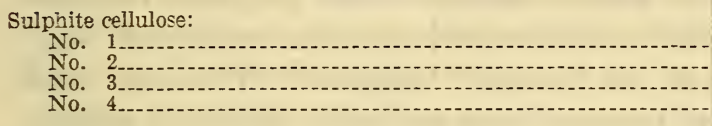 & $\begin{array}{l}28.33 \\
28.79 \\
25.98 \\
28.90\end{array}$ & $\begin{array}{l}24.80 \\
24.21 \\
23.82 \\
18.68\end{array}$ & $\begin{array}{l}53.4 \\
54.3 \\
52.1 \\
60.8\end{array}$ \\
\hline $\begin{array}{l}\text { Chestnut wood extract } \\
\text { Oak bark extract } \\
\text { Hemiock bark extract } \\
\text { Sulphited quebracho }\end{array}$ & $\begin{array}{l}27.33 \\
24.92 \\
27.45 \\
36.60\end{array}$ & $\begin{array}{l}13.74 \\
18.65 \\
17.05 \\
10.45\end{array}$ & $\begin{array}{l}66.5 \\
57.2 \\
61.7 \\
77.8\end{array}$ \\
\hline
\end{tabular}

Whereas the tannin contents of the sulphite cellulose extracts compare favorably with the other materials, the percentages of nontannins are higher and the values for purity proportionately lower. Since, in the tanning process, the nontannins build up in the liquors as the tannins are taken out by the hide substance, it is desirable to keep the nontannin content of an extract as low as practicable. This fact may have a bearing on the use of sulphite cellulose extracts as tanning agents by themselves, and to have caused them to be considered chiefly for filling purposes. It appears probable that a mixture of the sulphite and other extracts may be made in such proportions as to give a tanning blend of normal nontannin content. The making of a sulphite cellulose extract with a greatly reduced nontannin content is a probability, and one method of doing so has recently been described in the literature. ${ }^{2}$

A consideration of the other analytical results shows that these extracts are generally free from insoluble matters, but do have a high ash content. The latter is composed of bases in combination with the acid bodies of the waste liquor. The predomination of calcium, magnesium, or alumium depends upon the materials used in preparing the original sulphite liquors and in treating the waste liquor.

Traces of iron in an extract tend to produce a dark color in the leather. In sample No. 3 the percentage of iron is 0.028 , and a darker shade was shown in the color tests as compared with the other sulphite cellulose extracts.

The sulphite cellulose extracts are acid in character and the concentration of acid is greater than in most of the tanning materials produced from vegetable sources. The effective acidity, probably due to free lignosulphonic acids and possibly to some acetic acid, is a

The Leather Manufacturer, p. 73; March, 1926. 
desirable property. The $\mathrm{Ph}$ values of solutions of analytical strength ranged from 2.86 to 3.50 as compared with a range of from 3.7 to 4.7 for such generally used materials as chestnut wood, hemlock bark, wattle, oak bark, mangrove bark, and quebracho wood extracts.

\section{TANNING EXPERIMENTS}

The analyses described above showed that sulphite cellulose extracts contained materials which would combine with hide substance and would, therefore, be termed "tannins." The next work involved a number of trial tanning tests in which pieces of calfskin and samples of hide powder were tanned with these extracts alone. The results demonstrated that the hide substance was converted into a nonputrescible form which would withstand prolonged washing with water at ordinary temperatures without reverting to a raw condition. In other words, leather was thus produced. A series of experiments were then planned and conducted to indicate the value of these materials for tanning purposes.

(a) Color Tests.-In the manufacture of leather, particularly sole leather, color plays an important rôle. In order to be merchantable, the leather first must have a satisfactory color although the latter bears no relation to the most desirable property, that of resistance to abrasion. Satisfactory color is practically indefinable as a term and there are many varieties from which to choose. In general, however, the leather must have a uniform, light color to suit the requirements of the shoe industry. Thus it occasions no surprise that the tanner inquires as to what effect any proposed new material will have on the color of his finished leather, and further as to whether its use will aid in producing the color desired. These tests are usually carried out by tanning pieces of sheepskin or calfskin skivers (thin grain thicknesses of the skin) by procedures, which experience has shown give a satisfactory indication of color.

After trying several methods of making color tests the following one was found to be most satisfactory. The method is given because of the difficulty some have experienced in making color tests with sulphite cellulose extracts, synthetic tanning materials, and other special materials proposed for use in leather manufacture. A sample of sheepskin skiver (6 by 6 inches) was removed from the sodium chloride preserving solution and washed out in distilled water and then placed in $400 \mathrm{cc}$ of a $20^{\circ}$ barkometer (sp. gr. 1.02) liquor made from the material to be tested. The solution was shaken periodically and allowed to stand for 24 hours, after which the skiver was removed and washed for 24 hours with several changes of water and then placed in distilled water overnight, and finally rinsed. Next the skiver was drained for 30 minutes and then placed on a 
clean dry cloth in order that surplus water might be absorbed, after which it was dried in a dark room. When dry the skiver was sammied in damp sawdust for three or four hours, removed, thoroughly staked and trimmed.

By this procedure excellent samples of tanned leather were secured with all the sulphite cellulose extracts, which were soft, pliable, and light in color. In addition, samples were prepared using blends of sulphite cellulose extracts and other tanning materials to show the effect of their use in blends upon the color.

These color-test experiments were interpreted as showing that sulphite cellulose extracts would be satisfactory for tanning in so far as their effect on the color of the leather is concerned and that their use in blends with certain other tanning materials would have a beneficial and brightening effect on the color of the leather produced. The results of the color tests are illustrated in Figure 1 with samples of tanned sheepskin skivers. The light color characteristic of the sulphite cellulose extracts is evident. It will also be noted that by blending sulphite cellulose extracts with materials such as quebracho and cutch the red color of the latter is moderated. Blends with chestnut wood extract show a marked brightening of the color.

(b) Hide-Powder Tests. - Wilson and $\mathrm{Kern}^{3}$ have devised a method for determining the tannin content of tanning materials which, in general, gives lower results than those obtained with the A. L.C.A. method. In this method the solution of tanning material is first freed from tannin by shaking with hide powder and then the hide powder is freed from nontannins by prolonged and drastic washing. A modification of this method was used in determining the comparative tanning values of sulphite cellulose and several vegetable extracts. A solution of the materials to be tested was filtered to remove insolubles and the filtrate made up to contain $40 \mathrm{~g}$ of soluble solids to $600 \mathrm{cc}$ of solution. Twenty grams of dry hide powder were swollen in 150 cc of distilled water, and to this $600 \mathrm{cc}$ of the prepared tanning liquor was added. The sample was then tanned in the shaking machine (fig. 2) for 7 hours, allowed to stand overnight and again shaken for 5 hours. The total time of contact between the hide powder and tanning liquor was 29 hours.

The tanned hide powder was then squeezed in a linen bag and washed by percolation until the wash water gave a negative test for tannin with gelatin-salt solution. Further washing was done until the nontannins, not fixed by the hide powder, were removed, as indicated by the ferric-chloride test. The tanned hide powder was squeezed free of excess water, dried under room conditions, and placed

${ }^{3}$ The Chemistry of Leather Manufacture, pp. 215-231 (The Chemical Catalog Co., New York; 1923). 
in bottles for analysis. Moisture, ash, petroleum ether extract, and nitrogen were determined by the usual methods used for leather analysis. The combined tannin was taken as the difference between 100 and the sum of the hide substance ( $N \times 5.62)$, ash, moisture, and fats. The results of the experiments will be found in Table 3.

TABLE 3.-Analyses of tanned hide powders

\begin{tabular}{|c|c|c|c|c|c|}
\hline Hide powder tanned with- & Water & $\begin{array}{l}\text { Insolu- } \\
\text { ble ash }\end{array}$ & $\begin{array}{l}\text { Petro- } \\
\text { leum } \\
\text { ether } \\
\text { extract }\end{array}$ & $\begin{array}{l}\text { Hide } \\
\text { sub- } \\
\text { stance, } \\
N \times 5.62\end{array}$ & $\begin{array}{l}\text { Com- } \\
\text { bined } \\
\text { tannin } \\
\text { by dif- } \\
\text { ference }\end{array}$ \\
\hline $\begin{array}{l}\text { Chestnut weod } 1 \text {. } \\
\text { Do. }{ }^{2} \\
\text { Quebracbo Ord } 11 \\
\text { Do. }{ }^{2}\end{array}$ & $\begin{array}{r}\text { Per cent } \\
12.68 \\
12.05 \\
14.80 \\
14.66\end{array}$ & $\begin{array}{r}\text { Per cent } \\
0.11 \\
.13 \\
.20 \\
.16\end{array}$ & $\begin{array}{r}\text { Per cent } \\
0.30 \\
.33 \\
.35 \\
.28\end{array}$ & $\begin{array}{r}\text { Per cent } \\
54.70 \\
55.49 \\
54.55 \\
54.53\end{array}$ & $\begin{array}{r}\text { Per cent } \\
32.21 \\
32.00 \\
30.10 \\
30.37\end{array}$ \\
\hline $\begin{array}{l}\text { Oak Bark }{ }^{3} \ldots \ldots \\
\text { Do. }{ }^{2} \\
\text { Cutch i }{ }^{2}{ }^{2}\end{array}$ & $\begin{array}{l}14.00 \\
15.78 \\
16.00 \\
14.85\end{array}$ & $\begin{array}{l}.30 \\
.22 \\
.18 \\
.23\end{array}$ & $\begin{array}{l}.32 \\
.20 \\
.26 \\
.32\end{array}$ & $\begin{array}{l}54.34 \\
53.68 \\
54.53 \\
55.80\end{array}$ & $\begin{array}{l}31.04 \\
30.12 \\
29.03 \\
28.80\end{array}$ \\
\hline $\begin{array}{l}\text { Sulphite No. } 11 \\
\text { Do. } \\
\text { Sulphite No. }{ }^{2}{ }^{1} \\
\text { Do. }{ }^{2} \\
\text { Sulphite No. }{ }^{2}{ }^{1} \\
\text { Do. }{ }^{2}\end{array}$ & $\begin{array}{l}13.25 \\
14.25 \\
\text { 12. } 65 \\
\text { 14. } 60 \\
13.67 \\
13.45\end{array}$ & $\begin{array}{l}.26 \\
.31 \\
.29 \\
.18 \\
.32 \\
.34\end{array}$ & $\begin{array}{l}.22 \\
.30 \\
.20 \\
.24 \\
.18 \\
.24\end{array}$ & $\begin{array}{l}64.37 \\
63.94 \\
64.16 \\
62.88 \\
62.83 \\
63.59\end{array}$ & $\begin{array}{l}21.90 \\
21.20 \\
22.70 \\
22.10 \\
23.00 \\
22.38\end{array}$ \\
\hline
\end{tabular}

1 First series of experiments.

¿ Series of check experiments.

The $\mathrm{Ph}$ value for all tanning solutions was adjusted to 3.5. These tests show that, with solutions of the same acidity and soluble solids contents hide powder will fix from 70 to 75 per cent as much material from sulphite cellulose extracts as it will from the ordinary vegetable extracts, the time factor being constant. The experiments also show that the material fixed by hide powder from the sulphite cellulose extracts is so firmly held as to resist long washing with water at ordinary temperatures.

(c) Blends with Vegetable Extracts.-The effect of blending sulphite cellulose extracts with ordinary vegetable extracts was studied in order to determine whether the tannin content in the blended extract would show that an equal substitution could be made on the basis of tannin content. Samples of powdered chestnut wood, quebracho, and cutch were prepared and passed through a 60 -mesh sieve in order to secure uniform samples. These, together with a sample of sulphite cellulose extract No. 2, were analyzed for total solids, soluble solids, insolubles, nontannins and tannins, all solutions being adjusted to $\mathrm{Ph} 3.5$ before analysis. Solutions were then made up of quebracho, chestnut wood, and cutch containing one-third sulphite cellulose extract on the basis of tannin content. The blended solutions were then analyzed (A. L. C. A. method) and the results obtained compared with the calculated values for the analysis. 
Technologic Papers of the Bureau of Standards, Vol. 21

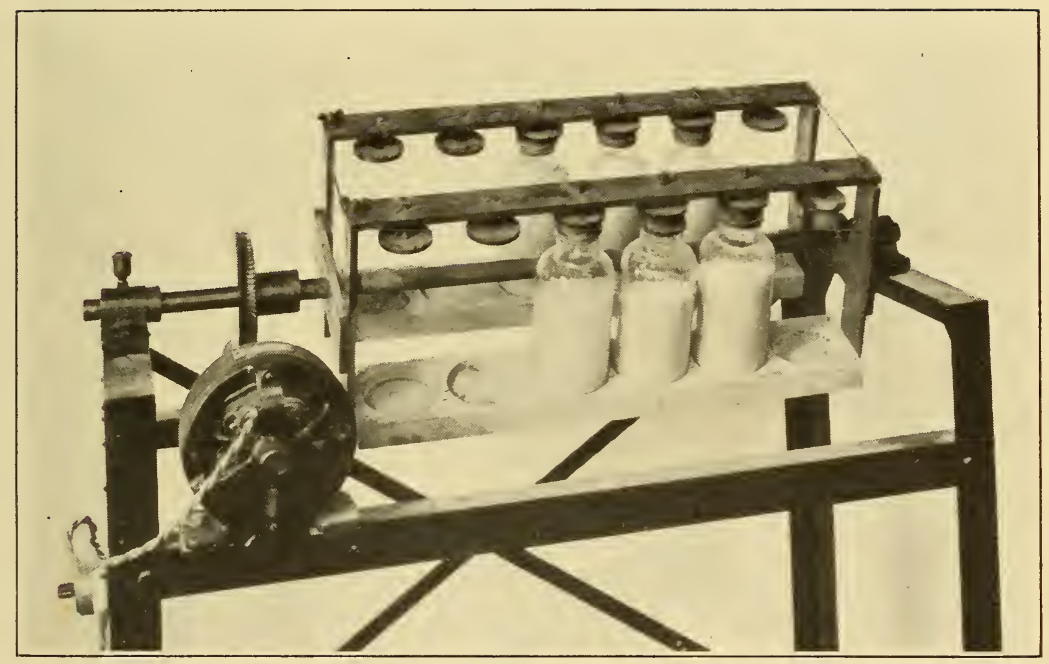

FIG. 2.- Shake bottle apparatus used in hide powder-tanning experiments 


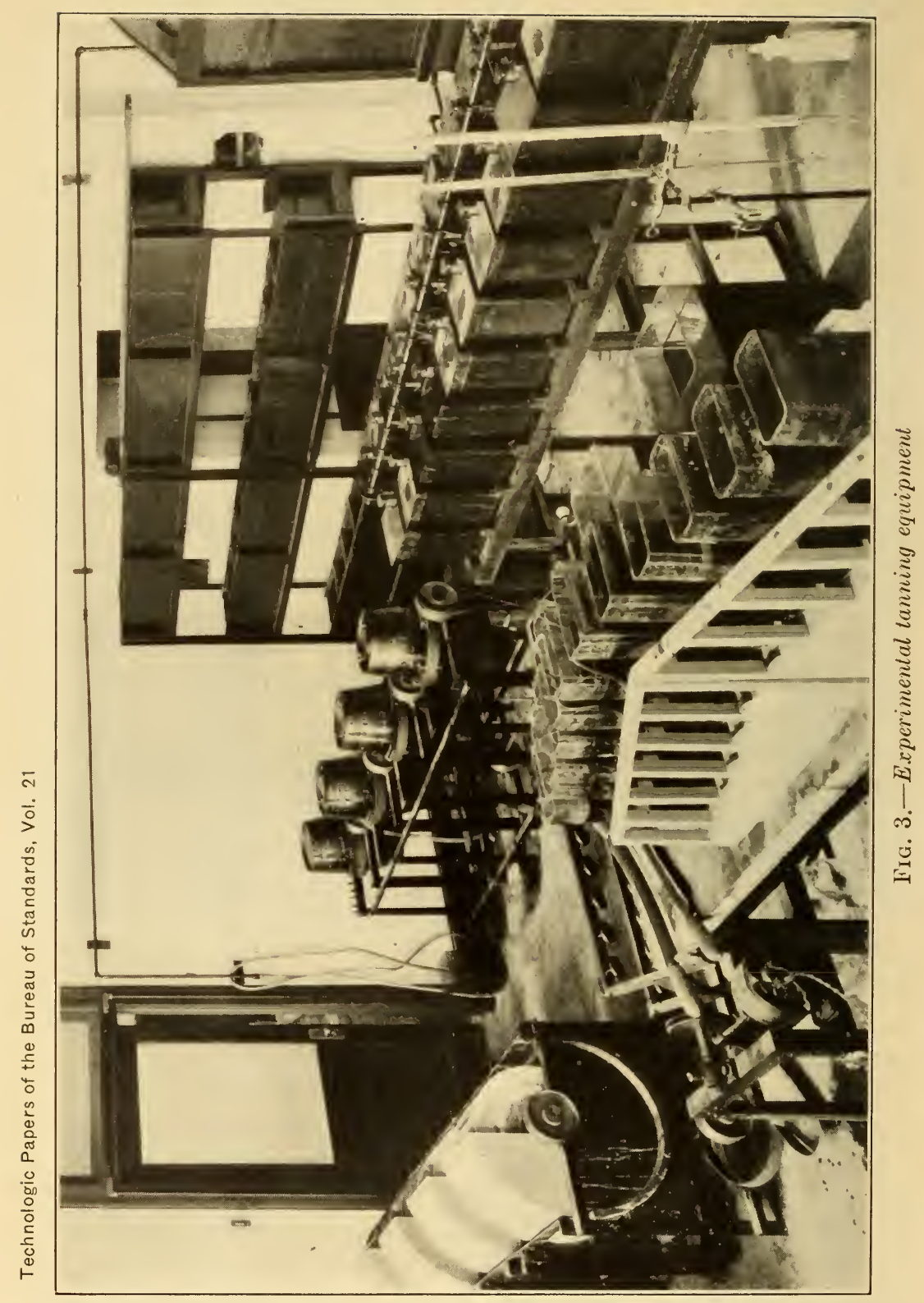


The results will be found in Table 4 in which each value represents the average of three individual tests.

TABLE 4.-Calculated and analytical results on blended extracts. Results expressed in grams per $100 \mathrm{cc}$ of solution of analytical strength. (Approximately $4 \mathrm{~g}$ tannin per $100 \mathrm{cc}$ )

\begin{tabular}{|c|c|c|c|c|c|c|}
\hline \multirow{2}{*}{ 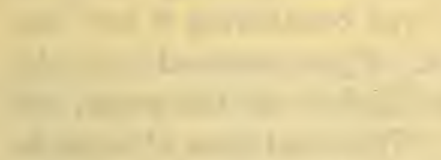 } & \multicolumn{2}{|c|}{$\begin{array}{l}\text { Blend No. I }(2 / 3 \text { que- } \\
\text { bracho, } 1 / 3 \text { sul- } \\
\text { phite No. } 2)\end{array}$} & \multicolumn{2}{|c|}{$\begin{array}{l}\text { Blend No. } 2 \text { (2/3 } \\
\text { chestnut, } 1 / 3 \text { sul- } \\
\text { phite No. } 2)\end{array}$} & \multicolumn{2}{|c|}{$\begin{array}{l}\text { Blend No. } 3(2 / 3 \\
\text { cutch, } 1 / 3 \\
\text { phite No. } 2)\end{array}$} \\
\hline & (a) & $(b)$ & (a) & (b) & (a) & (b) \\
\hline $\begin{array}{lll} & & \end{array}$ & $\begin{array}{r}0.600 \\
.564 \\
.036 \\
.137 \\
.427\end{array}$ & $\begin{array}{r}0.593 \\
.576 \\
.017 \\
.136 \\
.440\end{array}$ & $\begin{array}{r}0.607 \\
.603 \\
.003 \\
.213 \\
.389\end{array}$ & $\begin{array}{r}0.603 \\
.599 \\
.003 \\
.212 \\
.386\end{array}$ & $\begin{array}{r}0.604 \\
.600 \\
.004 \\
.103 \\
.405\end{array}$ & $\begin{array}{r}0.593 \\
.593 \\
.000 \\
.187 \\
.406\end{array}$ \\
\hline
\end{tabular}

Note.-(a) Caiculated resuits. (b) Analytical resuits.

It will be noted that the analytical results check very closely with the calculated amounts of the different ingredients. An interesting exception is in the case of the ordinary quebracho blend. The analytical result for insolubles was lower and for tannins higher than calculated. The sulphite cellulose extract appears to have acted upon the insolubles in the quebracho in such manner as to cause a portion of them to be determinable as tannins. From these results it appears that any proportional substitution of the ordinary vegetable extracts by sulphite cellulose on the basis of tannin content will not result in a lower tannin content for the blend than should be present as determined by calculation.

(d) Pretanning Experiments.-The tanning experiments on actual pieces of hide were carried out in the experimental tannery, a view of which is shown in Figure 3. The first series of tests consisted of the use of sulphite cellulose extract No. 1 as a pretannage. The green salted steer hides used were cut into strips 8 inches wide at right angles to the backbone. From these strips test pieces 10 inches long were cut, and each was marked so as to identify its location on the hide. The hide pieces were then subjected to the usual washing, soaking, fleshing, liming, and dehairing operations, after which they were placed in a cold water pool overnight to remove excess lime. They were then surface delimed in a weak lactic acid bath.

The hide pieces in this condition were introduced successively into vats of sulphite cellulose liquors containing $1 / 2,1$, and $1 \frac{1}{2}$ per cent tannin, respectively, and allowed to remain in each vat for 24 hours. These liquors, and those subsequently used in the yard proper, were agitated continuously with a mechanical stirrer. The hide pieces coming from the third sulphite liquor were completely struck through and had a light golden grain. They were then given a yard tannage with liquors consisting of a blend of $1 / 3$ quebracho, $1 / 3$ chestnut wood, 
and $1 / 3$ oak bark extracts made up on the brsis of tannin content. The first, or tail, liquor was maintained at a concentration of approximately 2 per cent tannin, which increased with succeeding liquors until a concentration of 4 per cent was reached in the last, or head, liquor. The hides were treated in seven liquors in this series and remained in each liquor for 48 hours. After completing the yard tannage they were placed in a lay-away vat containing 6 per cent tannin (approximately $70^{\circ} \mathrm{Bk}$.) for 7 days. Upon removal from this vat the leather was washed, bleached, oiled lightly on the grain, and dried. No filling with extracts was done. The total time of tannage, including the pretannage, the yard tannage, and the lay-away period, was 24 days.

Companion tests were made using liquors of the same strength and composition with the omission of the sulphite cellulose pretannage. As was expected, the high concentration of the early liquors caused a drawn grain and slow penetration. Further tests were made starting with a low concentration of tannin ( $1 / 4$ per cent), and it required 40 days in the liquors to produce leather of the same degree of tannage and yield as was secured with the pretannage.

Tests were also made with sulphite cellulose extract No. 2 in the manner described above excepting that a blend of 50 per cent sulphite cellulose and 50 per cent quebracho was used in the yard tannage. The series of liauors was so arranged that the total time of tannage was 28 days.

The color, fiber appearance, substance, physical properties, and chemical properties (Table 5) for the leathers tanned with the sulphite cellulose materials compared favorably with those of the leather tanned without these extracts.

The function of a pretannage is to so prepare the hide that it can be subjected to stronger liquors than would be possible without some preliminary treatment, and thus reduce the time required for tanning. The pretanning material must penetrate quickly, set the grain and fibers and produce the desired degree of swelling which is to be maintained throughout the tannage. The above tests with sulphite cellulose extract show that it can be used for a pretannage and that leather will be produced in from 24 to 28 days as compared with 40 days by the usual methods. A 70 per cent yield (ratio of the weight of the finished leather to the weight of the hide entering the liquors) was obtained by both methods. In practice the pretanning baths and the tail liquor of the yard eventually become so contaminated with salts, hide substance, and nontannins that they have to be discarded before the full tannin content is utilized. This makes the use of the pretannage of doubtful economic value. In these experiments it was found that six lots of hides could be run through the pretanning baths 
before there was evidence of sufficient contamination to impair the color of the leather.

(e) Tanning with Blended Liquors.-A series of tanning experiments were conducted using a straight yard tannage with a blend of $1 / 3$ sulphite celluose extract No. 2, $1 / 3$ chestnut wood extract, and $1 / 3$ cutch extract. The hides were prepared as described under the pretannage experiments and started in a weak liquor containing $1 / 4$ per cent tannin. They were run through a series of 14 liquors, the tannin content increasing until the head liquor contained 4 per cent. All liquors were continually agitated with a mechanical stirrer and the hides remained 48 hours in each liquor. After removal from the head liquor the hides were placed in a lay-away vat containing 6 per cent tannin $\left(70^{\circ} \mathrm{Bk}\right.$.) for 7 days. The total time of tannage was 35 days. The usual washing, bleaching, oiling and drying operations were made in finishing the leather. Ten lots of hides were run through these liquors and in each case the liquor, when discarded, contained less than $1 / 4$ per cent tannin, showing that the sulphite cellulose extract had been adsorbed by the hide along with the other materials used. The average yield of the 10 lots was 72 per cent and the degree of tannage averaged 68, varying from 66 to 71 for the different lots.

Companion tests were run using oak bark extract alone, and the time required to secure leather of the same degree of tannage and yield was 40 days.

In all tanning tests the time required was that found necessary by experiment to produce leather of approximately 70 degree of tannage.

These tests indicate that sulphite cellulose extracts may be blended with the usual vegetable extracts and satisfactorily used in the tanning stages. The economy of its use depends upon the comparative price per unit of tannin content and the efficiency with which the various materials may be utilized.

A factor to be considered in the use of sulphite cellulose extracts is that they are more acid in character than the ordinary vegetable extracts. These extracts can be so blended with the latter as to produce liquors of nearly the desired acidity. Thus the substitution of the more costly tanning materials by sulphite cellulose extracts leads also to the possible exclusion of those higher priced materials on which the tanner depends to produce acidity through fermentation. By blending in such proportions as to give an acid concentration slightly below that desired, the acidity can readily be adjusted by the use of lactic acid and an essentially sterile series of liquors secured in which the acidity can be more easily, accurately, and scientifically controlled.

( $f$ ) Evaluation of Tanned Leather.-In Table 5 will be found the chemical analyses for the various lots of leather tanned. 
TABLE 5.-Results of chemical analyses of tanned leather expressed in per cent

\begin{tabular}{|c|c|c|c|c|c|}
\hline Constituent & A & B & C & $\mathrm{D}$ & $E$ \\
\hline $\begin{array}{l}\text { Water solubles. } \\
\text { Hide substance } \\
\text { Grease (P. E. E.) } \\
\text { Moisture } \\
\text { Insoluble ash. } \\
\text { Combined tannin }\end{array}$ & $\begin{array}{r}6.00 \\
43.44 \\
2.49 \\
9.13 \\
.14 \\
33.80\end{array}$ & $\begin{array}{r}16.00 \\
42.00 \\
2.50 \\
10.00 \\
.16 \\
29.31\end{array}$ & $\begin{array}{r}17.03 \\
42.50 \\
1.97 \\
8.61 \\
.36 \\
29.53\end{array}$ & $\begin{array}{r}13.87 \\
43.85 \\
2.72 \\
8.14 \\
.20 \\
31.22\end{array}$ & $\begin{array}{r}17.16 \\
42.04 \\
2.56 \\
9.33 \\
28.73\end{array}$ \\
\hline $\begin{array}{l}\text { Total } \\
\text { Degree of tannage } \\
\text { Soluble tannins. } \\
\text { Total ash }\end{array}$ & $\begin{array}{r}\text { 100. } 00 \\
69.80 \\
1.79 \\
4.21 \\
.26\end{array}$ & $\begin{array}{r}100.00 \\
59.90 \\
11.21 \\
4.79 \\
.25\end{array}$ & $\begin{array}{r}100.00 \\
69.50 \\
12.36 \\
4.67 \\
.51\end{array}$ & $\begin{array}{r}100.00 \\
71.20 \\
.35\end{array}$ & $\begin{array}{r}100.00 \\
68.40 \\
13.19 \\
3.97 \\
.76\end{array}$ \\
\hline
\end{tabular}

A = Tanned with oak bark extract only (40 days).

$\mathrm{B}=$ Tanned with blend of $1 / 3$ chestnut wood, $1 / 3$ oak bark, and $1 / 3$ quebracho extracts ( 40 days).

$\mathrm{C}=$ Same as $\mathrm{B}$ except with a pretannage with sulphite cellulose extract No. 1 (24 days).

$\mathrm{D}=$ Pretanned with sulphite cellulose extract No. 2 and given further tannage with blend of 50 per cent sulphite No. 2 and 50 per cent quebracho ( 28 days).

$\mathrm{E}=$ Tanned with blend of $1 / 3$ sulphite cellulose extract No. 2, 1/3 cutch and 1/3 chestnut wood extracts. Results average for 10 lots of leather ( 35 days).

As reflected by the chemical analyses, the leathers tanned with the use of sulphite cellulose extract compare favorably with those tanned with the ordinary vegetable extracts (leathers $A$ and $B$ ).

The tensile strength, in pounds per square inch, was also satisfactory for leather in the condition of these samples. These results were $3,290,3,250,3,240,3,125$, and 3,570 , respectively, for samples $\mathrm{A}, \mathrm{B}, \mathrm{C}, \mathrm{D}$, and $\mathrm{E}$. The samples were in the rough leather condition, not having been rolled, stretched, or curried.

Although the amount of leather tanned was not sufficient for any comprehensive series of wear tests, a few soles tanned with the use of sulphite cellulose extracts (leather E, Table 5) were placed on shoes and found to wear as well as leathers not having these materials used in their manufacture.

The leather samples stored in the laboratory for six to eight months appear to have aged satisfactorily in so far as physical appearance is concerned. The sulphite cellulose extracts in the leather appeared to be stable as indicated by the determinations of $\mathrm{Ph}$ values of the leather solutions. These values, immediately after the leather was finished and again after six months, ranged from 3.3 to 3.6 and in no one sample was there indication of increased ionization.

An interesting point reflecting on the behavior of sulphite cellulose extracts in tanned leather is its detection by the Proctor and Hirsch method. Immediately after the leather was finished, the extract could be detected in the water soluble extract of the leather. After aging for a few months, however, no trace of the extract could be found by this test. Samples of leather from other sources said to contain large amounts of the extract were also tested and a negative result secured. In comparison with this situation, leathers 6 years old, which were filled but not tanned with sulphite cellulose extract, gave a very positive test for this material. 


\section{SUMMARY}

Following are briefly summarized the results of the investigation to indicate the value of sulphite cellulose extracts as tanning materials:

A. These extracts contain a satisfactory amount of tannins (material absorbable by hide powder) as determined by the generally accepted methods and compare favorably with vegetable tanning extracts in this respect.

B. The material in these extracts appears to be as firmly fixed by hide powder as the tannins from vegetable tanning extracts.

C. These extracts may be blended with the ordinary vegetable extracts without loss of tannin content in the blend as determined by calculation.

D. Color tests show them to be satisfactory for use in tanning.

E. Leather of good quality can be produced either by pretanning with these extracts and finishing with the ordinary vegetable extracts or by tanning with a blend of these and vegetable extracts.

F. The chemical, physical, and aging properties of the leather tanned with these materials compare favorably with those of leathers tanned without their use.

G. Their use as a pretannage or in blends with vegetable materials reduces the time required to produce leather of the same degree of tannage as is produced by the use of the ordinary vegetable tanning materials alone.

\section{CONCLUSION}

From the results of this investigation it is concluded that sulphite cellulose extracts have a value for tanning purposes, particularly when blended with the ordinary vegetable extracts. Their use would benefit the tanner by virtue of lowered production costs to the extent that they could be substituted for more costly materials and by decreasing the time required for tanning. The increased use of sulphite cellulose extracts would directly benefit the paperpulp producer and be of national economic benefit through the utilization of a material now largely wasted.

Washington, November 1, 1926. 

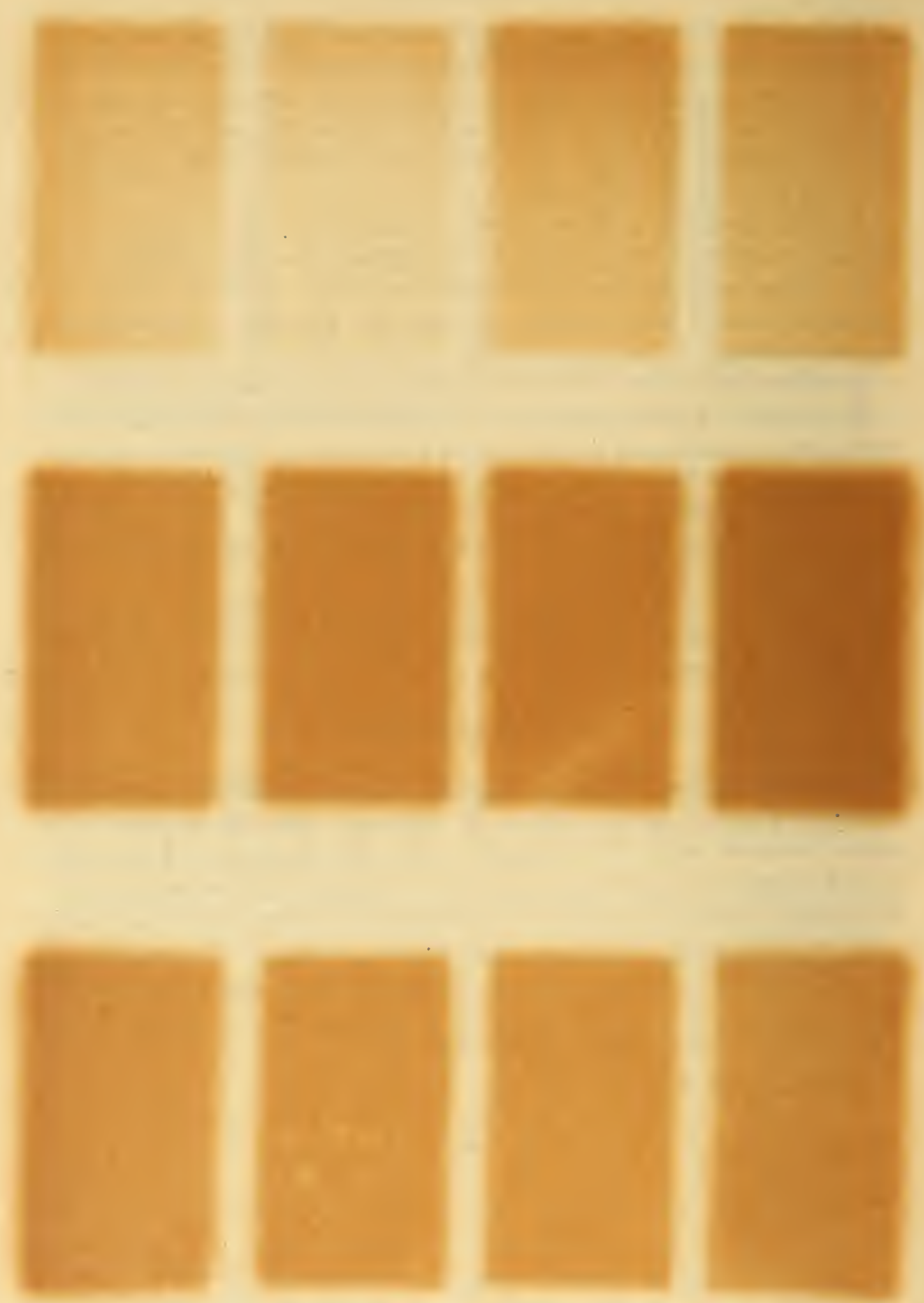
Technologic Papers of the Bureau of Standards, Vol. 21

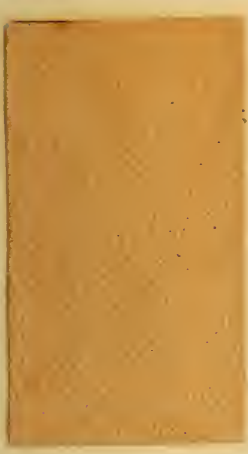

No. 1

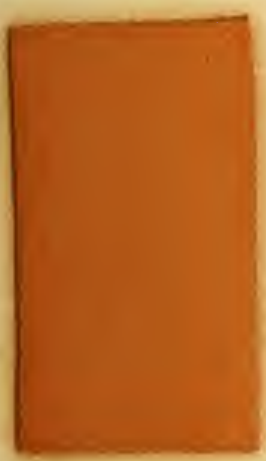

Ordinary Solid Quebracho Extract

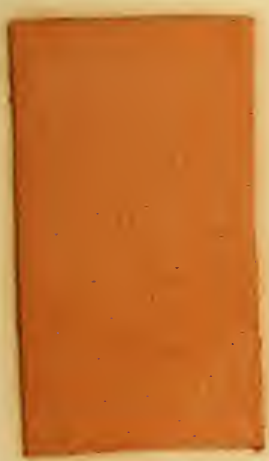

1/2 Quebracho $1 / 2$ S.C. E. No. 2

$33464^{\circ}-27$
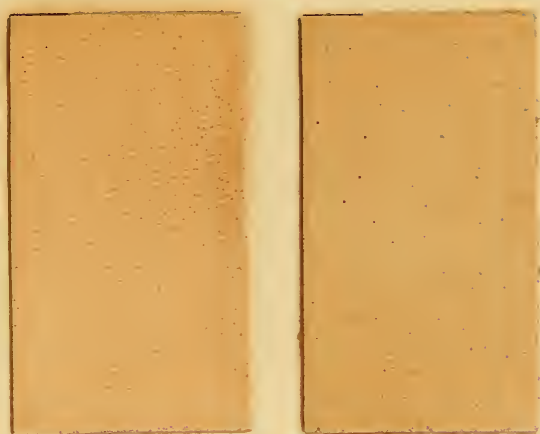

SULPHITE CELLULOSE EXTRACTS No. 2

No. 3

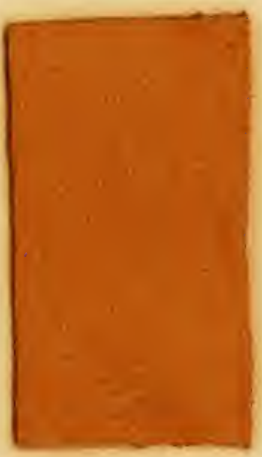

Cutch or Mangrove

Bark Extract

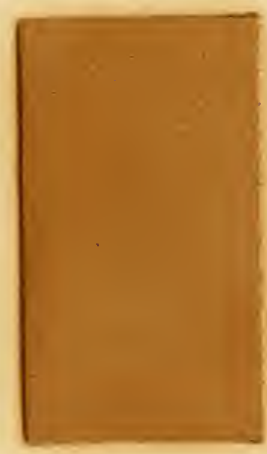

Chestnut Wood

Extract

Blend

S. C. E. No. 2

$1 / 3$ Cutch

$1 / 3$ Chestnut
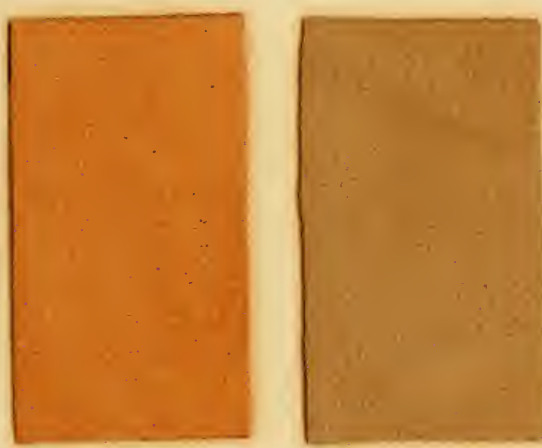

BLENDS

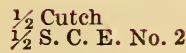

$1 / 2$ Chestnut

$1 / 2$ S. C. E. No. 2

1/3 Oak

$1 / 3$ Quebracho

$1 / 3$ S. C. E. No. 2

FIG. 1-Color tests 